\title{
Exponential growth of dental schools in Chile: effects on academic, economic and workforce issues
}

Ricardo Andrés Cartes-Velásquez

Deanery, Facultad de Odontología, Universidad de Concepción, Concepción, Concepción, Chile.

Declaration of Interests: The authors certify that they have no commercial or associative interest that represents a conflict of interest in connection with the manuscript.

\section{Corresponding Author:}

Ricardo Andrés Cartes-Velásquez

E-mail: cartesvelasquez@gmail.com

hitp://dx.doi.org/10.1590/S1806-83242013000600005

Submitted: Mar 19, 2013

Accepted for publication: Aug 06, 2013

Last revision: Aug 21, 2013
Abstract: In the last 30 years, Chile has undergone noteworthy economic development and an exponential growth in the access of its population to higher education. The aim of this paper was to review the changes in academic, economic and workforce issues that occurred as a consequence of the growth in supply of undergraduate dental vacancies between 1997 and 2011. Data collected from the Consejo de Educación Superior - CES, Comisión Nacional de Acreditación - CNA, and Instituto Nacional de Estadísticas de Chile - INE included these variables: number of dental schools, school type (private or traditional, see explanation below), city where the school is located, entry vacancies, total student enrollment, admission scores, percentile rank of dentistry as a university career, tuition fees, accreditation status, and number of inhabitants. There was an exponential increase in dental schools in Chile (5 to 34) that occurred in association with the rise in tuition fees (US\$ 3900 to US\$ 9800), a deterioration in the academic level of dental students (650 to 550 points in admission scores) and a predicted $77.5 \%$ oversupply of dentists by 2025 , according to WHO criteria. The exponential increase in dental schools in Chile brought about negative consequences, such as increasing career costs, deterioration in the academic level of dental students, and an oversupply of dentists, associated with lower incomes and possibly leading to unemployment. Additional research should be conducted to determine whether an increase in the number of dentists can improve the population's access to dental care and reduce the oral disease burden.

Descriptors: Education, Dental; Health Manpower; Chile.

\section{Introduction}

Historically, dentistry has been associated with a good standard of living and a level of complexity in its practice. Accordingly, educational access to this field has been reserved to young people with a high academic performance, and-because often accompanied by high tuition costs-to the higher classes, making it an elite career, very similar to medicine..$^{1-5}$

In the past 50 years, industrialized countries have seen a steady improvement in their oral health levels, mainly due to public health strategies aimed at promotion and prevention (fluoride, sealants, and hygiene). This contrasts with the increased levels of oral disease suffered by the inhabitants of developing countries ${ }^{6}$ such as Chile, or deprived populations, where there is great disparity in access to dental care, such as the 
US. ${ }^{7}$ This underscores the importance of preparing an appropriate workforce to face these demands. ${ }^{8}$

In Chile, dentistry is a six-year undergraduate course to which 17 to 18 year-old students can apply directly from high school by an admissions process that considers the results of an academic test (70\%-80\% weight) and the student's high school achievement scores (20\%-30\% weight). Up until 2003, this academic test corresponded to the Scholastic Aptitude Test (Prueba de Aptitud Académica - PAA), which focused on skills rather than knowledge. However, in 2003, the University Selection Test (Prueba de Selección Universitaria - PSU) was implemented; it focuses on the student's knowledge acquired in high school. This test covers four areas: mathematics, communication \& language, history and sciences, and it has a range of 150 to 850 points, with a median of 500 (110) points. ${ }^{9,10}$

In 2006, the National Accreditation Commission (Comisión Nacional de Acreditación, CNA) was created to ensure the quality of tertiary education (institutions, undergraduate programs, and postgraduate programs are accredited independently). However, CNA accreditation is voluntary and only guarantees that accredited institutions or programs will achieve minimum standards. Regrettably, in recent years, the CNA has been heavily criticized because of corruption scandals. ${ }^{9,10}$

Currently, the Chilean university system has two types of institutions: those created before 1981 are named "traditional," whether public or private, and those created since 1981 are called "private," comprising only private institutions. ${ }^{9}$

In the last 30 years, Chile has undergone noteworthy economic development (member of the Organisation for Economic Co-operation and Development - OECD since 2010 and close to reaching a per capita income of US\$20,000). It has also implemented many major social changes, resulting in an exponential growth in the access of its population to higher education, mainly due to private sector development, increasing the population coverage of higher education from $7.2 \%$ in 1981 to $50 \%$ in $2012,{ }^{9}$ an outcome which has also affected dentistry. ${ }^{11}$ However, there is no published research that analyzes the effects of this phenomenon on dental education issues.
The aim of this paper was to review the changes in academic, economic and workforce issues resulting from the growth in the supply of undergraduate dental vacancies between 1997 and 2011.

\section{Methodology}

This is a descriptive and retrospective study. Data collection was carried out using the INDICES (Indicadores de Instituciones y Carreras de Educación Superior) database of the Consejo Nacional de Educación - CNE, ${ }^{12}$ under the Ministerio de Educación de Chile - MINEDUC, which included the academic records of this database from 1997 to 2011. The variables considered for each year were:

- number of schools,

- school type (private or traditional),

- city where the school is located,

- entry vacancies,

- total student enrollment (first to sixth year),

- admission scores,

- percentile rank, and

- tuition fees, expressed by UF (Unidad de Fomento), a national measure that represents the country's inflation.

Career (school) accreditation status was requested from the $\mathrm{CNA}^{13}$ on October 27, 2012, and is based on the number of years of a school's accreditation (minimum of 1 and maximum of 7), in that more years imply better quality.

The evolution of dental graduates and their impact on the workforce for the 2012-2025 period was estimated taking into consideration the following conditions:

- a current workforce of 17,000 dentists, ${ }^{10}$

- no opening of new dental schools,

- no dentist immigration, and

- a graduation rate of $80 \%$ of students who entered dental school in 2005 and graduated 6 years later in 2011 (this is a conservative number considering that 1,200 dentists graduated in 2011, and 1,339 students enrolled in dental schools in 2005, meaning a $89.6 \%$ graduation rate).

It should be borne in mind that there is no need to obtain a license to practice or to pass a board 
Figure 1 - Number of private and traditional dental schools in Chile, 1997-2011.

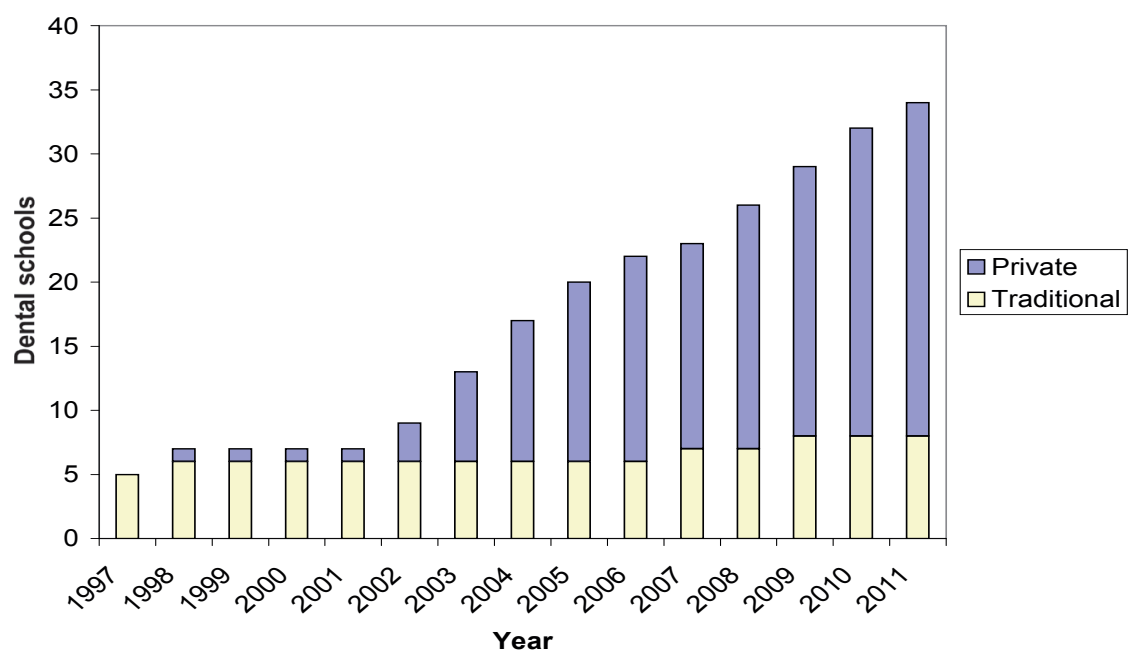

Figure 2 - Number of vacancies and total students at dental schools in Chile, 1997-2011.

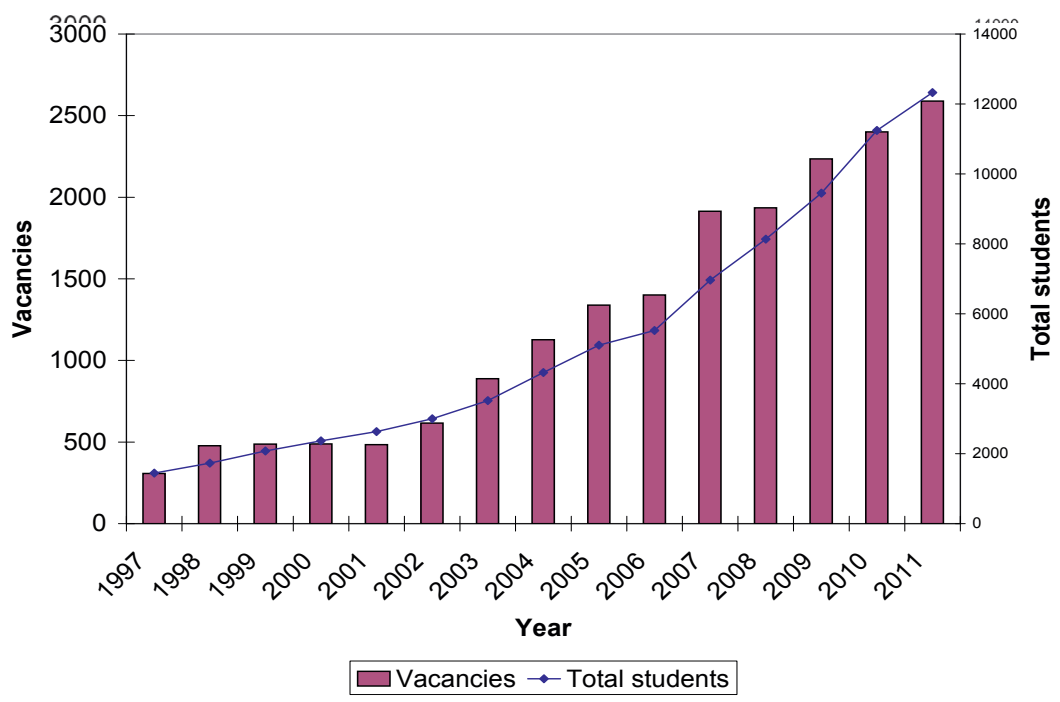

exam (national or state) in Chile; therefore, anyone can start practicing dentistry after she or he graduates.

National and regional (cities) population data were requested from the Instituto Nacional de Estadisticas de Chile. ${ }^{14}$ The data were tabulated and analyzed on an MS Excel 2003 (Microsoft Corporation, Redmond, USA) spreadsheet. The results are presented using descriptive statistics.

\section{Results}

From 1997 to 2011, the number of dental schools rose from 5 (belonging to 5 universities) to 34 (belonging to 20 universities), insofar as one university may have more than one dental school (Figure 1). This growth occurred mostly in the private sector, since many private universities have several schools in different cities of the country; for example, Universidad San Sebastian has 5 schools, Universidad Pedro de Valdivia has 4 schools, and Universidad Andrés Bello has 3 schools.

Entry vacancies increased from 303 to 2,589 in the 15 years analyzed, and the total enrollment grew from 1,447 to 12,325 students (Figure 2).

Tuition fees also increased at rates well above the inflation, rising from 80UF (US\$ 3,900) to 220UF (US\$ 9,800) as an annual average, and representing a real rise of $175 \%$, albeit with great differenc- 
es among schools, i.e., up to $74.5 \%$ (Table 1 ). This corresponds to a total career cost averaging US\$ 60,000 .

On the other hand, the average cutoff admission scores declined steadily from 650 to 550 points, although with a broad range of over 200 points between the first (highly selective) and fifth (less selec-

Table 1 - Mean, range and difference of annual dentistry costs in Chile, 1997-2011.

\begin{tabular}{c|c|c|c|c}
\hline Year & Mean (UF) & Min (UF) & Max (UF) & Diff (\%) \\
\hline 1997 & 80.62 & 71.29 & 93.31 & $31 \%$ \\
\hline 1998 & 111.57 & 88.12 & 157.20 & $78 \%$ \\
\hline 1999 & 115.59 & 98.43 & 171.06 & $74 \%$ \\
\hline 2000 & 120.35 & 101.24 & 176.98 & $75 \%$ \\
\hline 2001 & 120.90 & 100.42 & 167.12 & $66 \%$ \\
\hline 2002 & 128.56 & 103.94 & 174.92 & $68 \%$ \\
\hline 2003 & 156.95 & 105.49 & 210.98 & $100 \%$ \\
\hline 2004 & 163.30 & 112.89 & 209.03 & $85 \%$ \\
\hline 2005 & 174.15 & 119.01 & 231.63 & $95 \%$ \\
\hline 2006 & 179.62 & 128.32 & 245.43 & $91 \%$ \\
\hline 2007 & 186.87 & 125.11 & 248.32 & $98 \%$ \\
\hline 2008 & 186.90 & 123.95 & 235.63 & $90 \%$ \\
\hline 2009 & 187.31 & 125.78 & 236.58 & $88 \%$ \\
\hline 2010 & 209.66 & 161.18 & 259.30 & $61 \%$ \\
\hline 2011 & 219.38 & 158.85 & 277.16 & $74 \%$ \\
\hline
\end{tabular}

Min: minimum; Max: maximum; Diff: difference. tive) quintile of dental schools. In 1997, the range between highest and lowest cutoff admission scores was 40 points (637-677), compared with 242 points (481-723) in 2011. This has meant a loss in the academic ranking of dentistry, measured by percentile rank, compared to other university careers (Figure 3 ).

Currently, there is one vacancy for entry into dentistry for every 6,662 inhabitants in Chile. The highest concentration of schools and available vacancies are in Santiago, with 11 dental schools and 1,140 vacancies, Concepción, with 6 dental schools and 456 vacancies, and Valparaiso, with 3 dental schools and 371 vacancies. In regard to the population size, the largest ratio of entry vacancies to inhabitants is in Concepcion ( 1 to 4,466), followed by Valparaíso (1 to 4,742), and Santiago (1 to 6,038).

In regard to accreditation, only 9 universities are accredited (12 dental schools) and 2 are applying for accreditation for the first time (6 dental schools). The remaining 9 universities (16 dental schools) have never applied for accreditation for their undergraduate dentistry programs. Considering that the maximum possible accreditation undergraduate dentistry program is 7 years, 3 universities have been accredited for 4 years, 4 for 5 years, and 2 for 6 years.

The workforce projection (Figure 4) shows an increase from 17,000 dentists in 2012 to 42,428 in 2025 , representing an inhabitant to dentist ratio of 1,023 and 450 , respectively.

Figure 3 - Admission cutoff score (PAA/PSU) and percentile rank over the entire university system for entry into dentistry in Chile, 1997-2011.

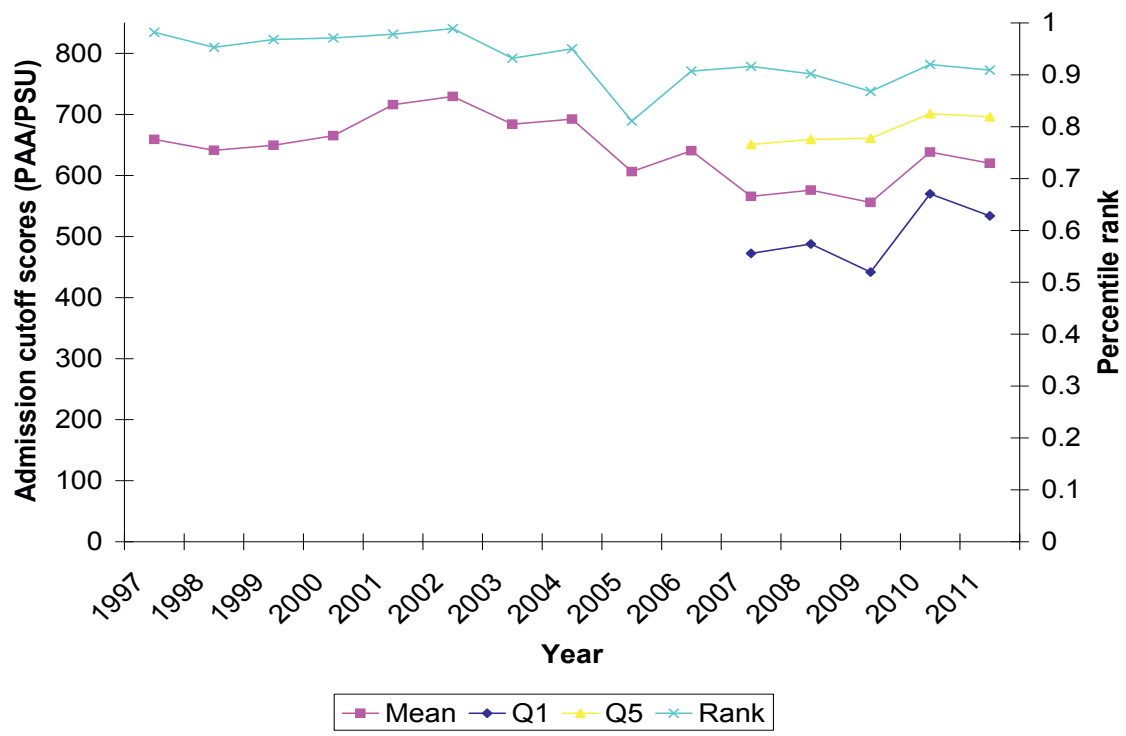


Figure 4 - Projection of dental workforce and ratio of inhabitants per dentist in Chile, 2012-2025.

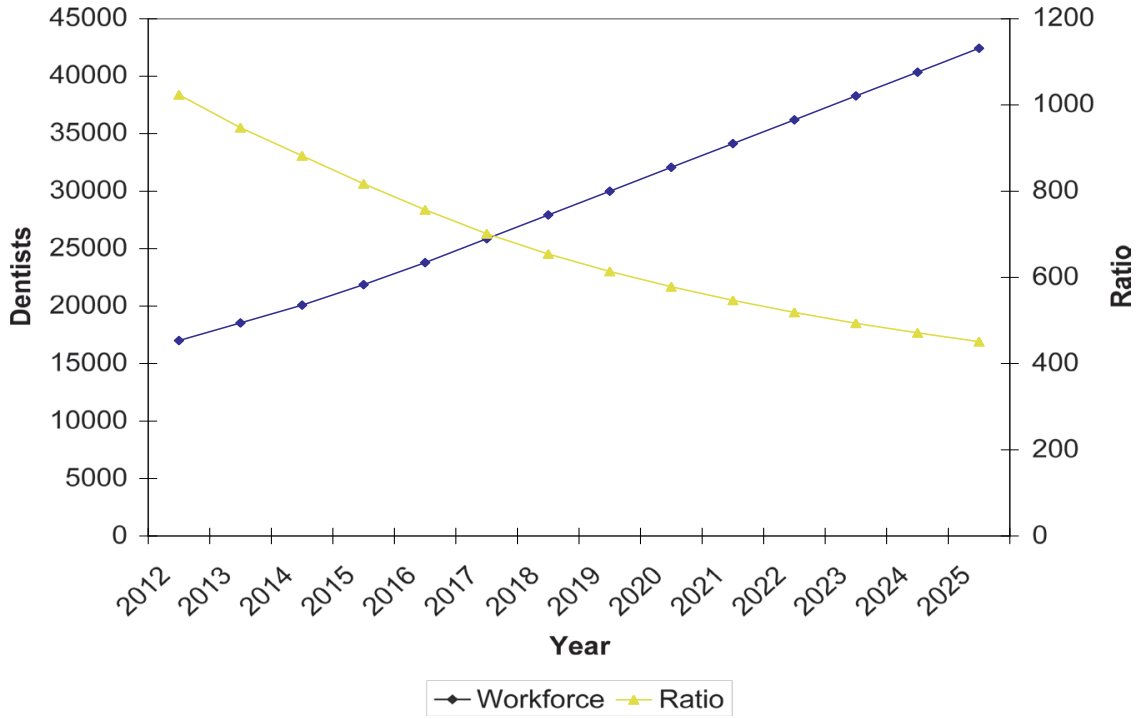

\section{Discussion}

It is noteworthy to explain an important limitation of these results. Although the data were collected from an official source (Consejo Nacional de Educación - CNE de Ministerio de Educación de Chile) there are two faults. First, part of the academic records were incomplete (PAA/PSU scores), mainly those for the dental schools of private universities. Second, not all institutions were registered, which means that in 2011, according to the data of the Colegio de Cirujano Dentistas de Chile A. G., there were actually 39 and not 34 dental schools in Chile. $^{10}$

Chile has shown significant growth in enrollment at the tertiary level, rising from 370,798 in 1997 to a projected 1 million students in 2012, representing a growth of $170 \%$, and a significant increase in the population coverage. ${ }^{9}$ Chile's expensive education has been strongly criticized, because it has been driven primarily by market criteria, which are not in line with the developmental needs of the country. It has also been associated with a high dropout rate (roughly 50\% of students who start a course never end it). It is the most expensive higher education system in the world, checks the access of poor people to education, and implies that over $80 \%$ of tuition fees must come from a family's pocket. ${ }^{11,15,16 .}$

In the case of dentistry, this growth has been over 8 -fold in just 15 years. This surpasses the steady ex- pected growth, fueled by other factors, such as the high social value of the profession, alongside medicine, ${ }^{4,5}$ which has also seen an explosive growth in the supply of dental professionals, in Latin America, and especially in Chile. ${ }^{17,18}$ This makes Chilean universities a highly profitable industry, even though profit is legally forbidden in Chilean university education. ${ }^{10}$

In light of this scenario, the rise in tuition fees for dentistry is an expected phenomenon, but the magnitude has been excessive. This rise contrasts with the low accreditation rates, below 25\%, recalling that accreditation just implies minimum standards of quality that in no way assure an excellent level of education or professional dentistry.

Another consequence has been the academic level of dental students. At the beginning of the period studied (1997), dentistry certainly represented an elite academic career, and witnessed the enrollment of students from the group of the best $1 \%$ to $2 \%$ of high school graduates. This situation changed dramatically after 2003, with a progressive decline in student scores and in the ranking of dentistry as a university career, in comparison with other careers. This coincided with the opening of new dental schools, mostly private. In fact, there are dental schools enrolling students who made 304 points on their PSU University Selection Test (equivalent to 5\% of students with the poorest performance; the PSU 
has a mean of 500 points and a standard deviation of 110 points). ${ }^{9}$

Research productivity is another important aspect to be considered. Until now, despite the increase in the scientific output of Chilean dentistry over the first decade of this century, ${ }^{19}$ the new universities have contributed to this increase only marginally or not at all. ${ }^{11}$

The consequences to the dental workforce continue to be dramatic: projections by the Colegio de Cirujano Dentistas de Chile A. G. indicate that, between 2001 and 2011, the number of dentists doubled, and that there were approximately 17,000 dentists in 2012, equivalent to one dentist per thousand inhabitants. ${ }^{10}$ In the short term, the number of dentists in the country is expected to double again, and this is taking into account only those who graduated from registered dental schools in Chile. Added to this are the immigrant dentists and those graduates who are not from registered schools. With this in mind, the estimate of over 42,000 dentists in 2025, one for every 450 inhabitants, is probably underestimated. We should remember that the WHO recommendation for developing countries is 1 dentist per 2,000 inhabitants. ${ }^{9}$ This means that, in 2025 , the oversupply of professionals will be about 4 for every 5 dentists. In spite of this, access to dental care today is limited by high costs in the private healthcare system and low coverage in the public healthcare system, as well as by the lack of dental insurance. Therefore, we have two types of people: healthy ones with access to dental care and sick ones without access. ${ }^{20}$

Situations like these in Chile can be seen in neighboring countries, like Brazil, where there was an exponential growth between 1995 and 2008, especially in private dental schools, resulting in the creation of 102 institutions in thirteen years. However, there was an unequal distribution of professionals, resulting in a lack of dental coverage for a large portion of the Brazilian population. ${ }^{21}$ Nonetheless, Brazil has developed a strong and clear policy for the higher education of healthcare professionals over recent years, especially to address the shortage in physicians and nurses. ${ }^{22}$ Comparatively, the conditions in Brazil differ very much from those in Chile, where there was an implicit policy driven by market criteria. ${ }^{15,16}$

A similar situation occurred in Colombia, where there was an increase in dental schools from 5 in 1969 to 21 in 2010, mostly private. ${ }^{23}$ This rise has been strongly criticized because of the lack of planning of human talent in oral health and the negative consequences of an oversupply of labor, unemployment and job insecurity for dentists. ${ }^{24}$

As for other healthcare professions in Chile, like kinesiology and nursing, the situation is even more alarming in regard to the number of universities offering these careers; future research into these professions is necessary. ${ }^{17}$

The economic consequences are not just related to tuition fees for dentistry. According to the records of the Servicio de Impuestos Internos de Chile - SII, ${ }^{10}$ between 2009 and 2010, there was a decrease of $21.2 \%$ in the monthly income declared by dentists, down from US $\$ 2,300$ to US $\$ 1,810$. This corresponds to an income of US\$21,720 per year, far short of the US\$143,310 earned in the US. ${ }^{3}$ These data differ from those provided by the Ministerio de Educación de Chile, which show an average monthly income of US\$ $2,750 .{ }^{25}$

Future lines of research to be explored should address:

a. the quality of teaching in dental schools, especially those where admission scores are extremely low and those that are not accredited;

b. the reinvention/innovation of dentists who cannot work as dentists;

c. job satisfaction levels;

d. the urban-rural distribution of the workforce and the reduction in disparity of access to dental care;

e. the evolution of specialist dentists; and,

f. the development of the social value of a dental career.

\section{Conclusion}

There was an exponential increase in dental schools in Chile in the period from 1997 to 2011, which brought about negative consequences, such as increasing career costs, deterioration in the academic level of dental students, and an oversupply 
of dentists, associated with lower incomes and possibly leading to unemployment. Future research should be conducted to determine whether the in-

\section{References}

1. Mariño RJ, Morgan MV, Winning T, Thomson WM, Marshall RI, Gotjamanos T, et al.. Sociodemographic backgrounds and career decisions of Australian and New Zealand dental students. J Dent Educ. 2006 Feb;70(2):169-78.

2. Gallagher JE, Clarke W, Eaton KA, Wilson NH. Dentistry - a professional contained career in healthcare. A qualitative study of Vocational Dental Practitioners' professional expectations. BMC Oral Health. 2007 Nov 16;7:16.

3. Hawley NJ, Ditmyer MM, Sandoval VA. Predental students' attitudes toward and perceptions of the dental profession. J Dent Educ. 2008 Dec;72(12):1458-64.

4. Rich AM, Ayers KM, Thomson WM, Sinclair RJ, Rohan MJ, Seymour GJ. Does performance in selection processes predict performance as a dental student?. Eur J Dent Educ. 2012 Feb;16(1):27-34.

5. Buyse T, Lievens F, Martens L. Admission systems to dental school in Europe: a closer look at Flanders. Eur J Dent Educ. 2010 Nov;14(4):215-20.

6. World Health Organization. Oral Health Database [homepage]. Geneva: World Health Organization; 2012 [cited 2012 Oct 31]. Available from: http://www.who.int/oral_health/ databases/global/en/index.html.

7. Hilton IV, Lester AM. Oral health disparities and the workforce: a framework to guide innovation. J Public Health Dent. 2010 Jun;70 Suppl 1:S15-23.

8. Garcia RI, Inge RE, Niessen L, DePaola DP. Envisioning success: the future of the oral health care delivery system in the United States. J Public Health Dent. 2010 Jun;70 Suppl 1:S5865 .

9. Espinoza O, Gonzalez LE. Access to higher education in Chile: a public vs. private analysis. Prospects. 2013 Jun; 43(2):199214.

10. Monsalves MJ. The dentistry what we have and don't want: criticism of the current situation. Rev Chil Salud Publica. 2012 Aug;16(2):241-6.

11. Uribe S, Pradenas I, Urriola M. Impact of the increase of dental schools on the chilean dental scientific productivity. Rev Clin Periodoncia Implantol Rehabil Oral. 2012 Apr;5(1):13-9.

12. Consejo Nacional de Educación (República de Chile). INDICES Estadísticas [homepage]. Santiago de Chile: Ministerio de Educación de Chile; 2012 [cited 2012 Oct 25]. Available from: http://www.cned.cl/public/secciones/SeccionIndicesEstadisticas/indices_estadisticas_sistema.aspx. crease in the number of dentists can improve the population's access to dental care and reduce the oral disease burden.

13. Comisión Nacional de Acreditación [homepage]. Santiago de Chile: Ministerio de Educación de Chile; 2012 [cited 2012 Oct 27]. Available from: http://www.cnachile.cl/oirs/resultadosdeacreditacion/?buscar=true\&name1= 10 .

14. Demográficas y Vitales. Instituto Nacional de Estadísticas INE. 2012 [homepage]. Santiago de Chile: Instituto Nacional de Estadísticas de Chile; 2012 [cited 2012 Oct 28]. Available from: http://www.ine.cl/canales/chile_estadistico/familias/ demograficas_vitales.php.

15. Pressacco C, Carbone R. Higher education in Chile: Tensions and relevant actors around the quality equity axis. Pap Polit (Bogota). 2010 Jul-Dec;15(2):537-70.

16. Redondo JM. The chilean experimentation in education: Does it conduct greater equity and quality in the education? Ultima Decada. 2005 Aug;13(22):95-110.

17. Medina E, Kaempffer R. The health careers teaching system in Chile. Rev Med Chil. 2007 Oct;135(10):1346-54. Spanish.

18. Roman O. The new medical schools in Chile and their influence on the medical scenario. Rev Med Chil. 2009 Aug;137(8):1099-104. Spanish.

19. Cartes-Velasquez R, Aravena Torres P. Bibliometric profile of chilean dentistry, 2001-2010. Rev Clin Periodoncia Implantol Rehabil Oral. 2012 Apr;5(1):5-8. Spanish.

20. Abadía Barrero C. Poverty and inequalities: an obligatory dental health debate. Acta Bioeth. 2006 Jan;12(1):9-22.

21. Saliba NA, Moimaz SA, Garbin CA, Diniz DG. Dentistry in Brazil: its history and current trends. J Dent Educ. 2009 Feb;73(2):225-31.

22. Victora CG, Barreto ML, Leal MC, Monteiro CA, Schmidt MI, Paim J, et al.. Health conditions and health-policy innovations in Brazil: the way forward. Lancet. 2011 Jun 11;377(9782):2042-53.

23. Jaramillo JA, Ternera Pulido JH, Castro Núñez JA, Bird WF, Komabayashi T. Dental education in Colombia. J Oral Sci. 2010 Mar;52(1):137-43

24. Ternera J. Human talent planning oral health in Colombia. Acta Odontol Colomb. 2011 Jan;1(1):77-92.

25. Mifuturo [homepage]. Santiago de Chile: Ministerio de Educación de Chile; 2012 [cited 2012 Oct 28]. Available from: http://www.mifuturo.cl/index.php/component/tbusc $\mathrm{a} /$ ?view=futurolaboral\&tmpl=component\&layout=detail $\&$ ID $=$ ' $165^{\prime}$ 